\title{
GABA and Lioresal Actions on the Identified Onchidium Neuron
}

\author{
Nobuaki Shimizu, Norio AKaIKe, Yutaka Oomura, \\ Juro Maruhashi, ${ }^{*}$ and Manfred R. KLEE** \\ Department of Physiology, Faculty of Medicine, Kyushu University, \\ Fukuoka, Fukuoka, 812 Japan \\ *Department of Biology, Daiichi College of Pharmaceutical Sciences, \\ Fukuoka, Fukuoka, 815 Japan \\ ** Max-Planck Institute, Frankfurt, Germany
}

\begin{abstract}
Responses of identified single neurons in the isolated right cerebral ganglion of Onchidium to bath applied $\gamma$-aminobutyric acid (GABA) and lioresal (LRS) were measured using conventional intracellular microelectrode techniques under current and voltage clamp conditions. In normal medium the neurons responded to both GABA and LRS. GABA induced two successive hyperpolarizations (phase I and II). Phase I was a short-lasting $\mathrm{Cl}^{-}$permeability increase while phase II was a long-lasting $\mathrm{K}^{+}$permeability increase. LRS evoked only a long-lasting $\mathrm{K}^{+}$permeability increase. In $\mathrm{Ca}^{2+}$-free high $\mathrm{Mg}^{2+}$ medium GABA produced only short-lasting hyperpolarization while LRS had no effect. GABA-induced phase I responses behaved as a simple $\mathrm{Cl}^{-}$electrode following changes of external $\mathrm{Cl}^{-}$concentrations. The Hill coefficient obtained from the relation between the relative change in the GABA current and the GABA concentration was almost one during the current increase phase in $\mathrm{Ca}^{2+}$-free high $\mathrm{Mg}^{2+}$ medium. These results indicate that GABA has a direct $\mathrm{Cl}^{-}$permeability increase action on the postsynaptic cell membrane of the identified Onchidium neuron while LRS has no such direct action.
\end{abstract}

Key Words: Onchidium, neuron, GABA, lioresal, $\mathrm{Cl}^{-}$current.

Lioresal (LRS), the $\beta$-( $\rho$-chlorophenyl) derivative of $\gamma$-aminobutyric acid (GABA) has been thought to be GABA-mimetic at neuronal receptors. Recent$1 y$, it has been reported that there is evidence for and against a GABA-mimetic action of LRS (NAIK et al., 1976; DAVIDOFF, 1978; Fox et al., 1978; PoTASHNER, 1979; Waddington and Cross, 1979; Bowery et al., 1980; WAdDington and Cross, 1980). In an identified Onchidium neuron immersed in sea water having

Received for publication January 14, 1983

清水宣明，赤池紀扶，大村 裕，丸橋寿郎 
half $\mathrm{Ca}^{2+}$ and 3 times $\mathrm{Mg}^{2+}$, GABA produces hyperpolarization in two phases, i.e. a short-lasting $\mathrm{Cl}^{-}$permeability increase followed by a rapid desensitization and a long-lasting $\mathrm{K}^{+}$permeability increase, while LRS elicites only a long-lasting hyperpolarization resulting from $\mathrm{K}^{+}$permeability increase (OOMURA et al., 1979, 1982). In our recent preliminary experiments, however, the Onchidium neuron perfused with sea water containing half $\mathrm{Ca}^{2+}$ and 3 times $\mathrm{Mg}^{2+}$ could still elicit IPSPs, and the presynaptic activities could be blocked only by a continuous perfusion of $\mathrm{Ca}^{2+}$-free high $\mathrm{Mg}^{2+}$ solution containing $\mathrm{Co}^{2+}$ for 20 to $30 \mathrm{~min}$. The long-lasting hyperpolarization to both GABA and LRS decreased in parallel with the decrease of IPSPs amplitude in $\mathrm{Ca}^{2+}$-free high $\mathrm{Mg}^{2+}$ solution. Therefore, the aim of the present experiments is to examine quantitatively whether GABA and LRS have a direct action on postsynaptic soma membrane of the identified Onchidium neuron under current and voltage clamp conditions.

\section{MATERIALS AND METHODS}

The identified neuron in the isolated right cerebral ganglion of Onchidium was used (Fig. 1). The experimental set up was similar to that of previous studies (OOMURA et al., 1979). Briefly intracellular microelectrodes were filled with $0.7 \mathrm{M}$ $\mathrm{K}_{2} \mathrm{SO}_{4}$. Two microelectrodes were inserted into an identified single neuron, one being used to pass current and the other to record membrane potential.

The ionic composition (mM) of normal artificial sea water was the same as that in the previous report (OomurA et al., 1979): $\mathrm{NaCl}, 457.6 ; \mathrm{KCl}, 9.6 ; \mathrm{CaCl}_{2}$, $10.4 ; \mathrm{MgCl}_{2}, 48.5 ; \mathrm{pH} 7.5$ by Hepes-NaOH. $\mathrm{Ca}^{2+}$-free high $\mathrm{Mg}^{2+}$ sea water had

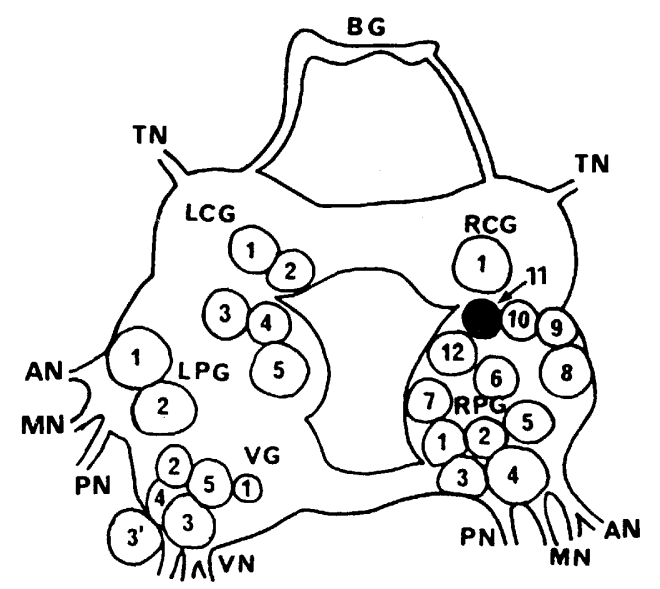

Fig. 1. A schematic illustration of the dorsal view of the Onchidium oesophageal ganglia. The GABA-sensitive neuron, \#11 (indicated by an arrow), is located in the right cerebral ganglion (RCG). LCG, left cerebral ganglion; LPG and RPG, left and right pleural ganglions; AN, MN, and PN, anterior, medial, and posterior pleural nerves; TN and $\mathrm{VN}$, tentacle and visceral nerves. 
the following composition (mM): $\mathrm{NaCl}, 400 ; \mathrm{KCl}, 9.6 ; \mathrm{CoCl}_{2}, 10 ; \mathrm{MgCl}_{2}, 100$; $\mathrm{pH}$ 7.5. The $\mathrm{Ca}^{2+}$-free high $\mathrm{Mg}^{2+}$ test solutions containing various concentrations of $\mathrm{Cl}^{-}$were made by replacing $\mathrm{Cl}^{-}$with an equimolar isethionate ${ }^{-}$in the external solution while increase of $\mathrm{Cl}^{-}$was made by adding extra $\mathrm{NaCl}$ to the medium. Preparations were superfused at a rate of $2 \mathrm{ml} / \mathrm{min}$.

The ionic currents during voltage clamp were stored on a tape recorder and plotted directly by a pen-writing recorder. GABA (Tokyo Kasei) and LRS (CibaGeigy) were dissolved in test solution just before use, and the drugs were examined by bath application. All experiments were carried out at room temperatures of 18 to $21^{\circ} \mathrm{C}$.

\section{RESULTS}

\section{Ionic mechanism}

In normal artificial sea water, two different types of hyperpolarizing responses to $3 \mathrm{~mm}$ GABA were observed in this identified neuron (Fig. 2A). The present results were quite similar to those reported by OOMURA et al. (1979). The phase I hyperpolarization was rapid, peaking at about $30 \mathrm{sec}$, and was followed by desensitization. It resulted exclusively from an increased conductance to $\mathrm{Cl}^{-}$, since the responses were sensitive to external $\mathrm{Cl}^{-}$concentration and picrotoxin. The results were also the same as the results of Oomura et al. (1982). The GABAinduced phase II hyperpolarization increased to a maximal value in 3 to $4 \mathrm{~min}$, and the increased conductance continued for an additional $10 \mathrm{~min}$ even after washing out GABA by normal external solution. According to Oomura et al. (1982), the phase II hyperpolarization results from the increased conductance to $\mathrm{K}^{+}$. On the other hand, LRS produced only a continuous tonic hyperpolarization resulting from $\mathrm{K}^{+}$conductance increase as shown in Fig. 2B.

Involvement of $\mathrm{Na}^{+}$in GABA- or LRS-induced potential and conductance changes was tested by replacing external $\mathrm{NaCl}$ with an equimolar Tris $\mathrm{Cl}$. Neither of the two successive hyperpolarizations nor the conductance increases produced by GABA were diminished. LRS action was also hardly affected by the $\mathrm{Na}^{+}$-free medium. In the same cell, the substitution of isethionate ${ }^{-}$for external $\mathrm{Cl}^{-}$markedly changed only the GABA-induced short-lasting hyperpolarization. The concentration changes of external $\mathrm{K}^{+}$affected on GABA- and LRS-induced longlasting hyperpolarization. The qualitative results about the relationship between GABA response and the external $\mathrm{K}^{+}$or $\mathrm{Cl}^{-}$concentration were already reported from our laboratory (OOMURA et al., 1982).

When the bathing medium was exchanged from a normal medium to a $\mathrm{Ca}^{2+}$. free high $\mathrm{Mg}^{2+}$ medium, considerable fluctuations of resting membrane potentials and bursts of action potentials were evoked and continued for at least 20 to $30 \mathrm{~min}$. Thereafter, the synaptic inputs on the postsynaptic cell membrane and the spontaneous action potentials ceased, at which time current injection could elicit a full 

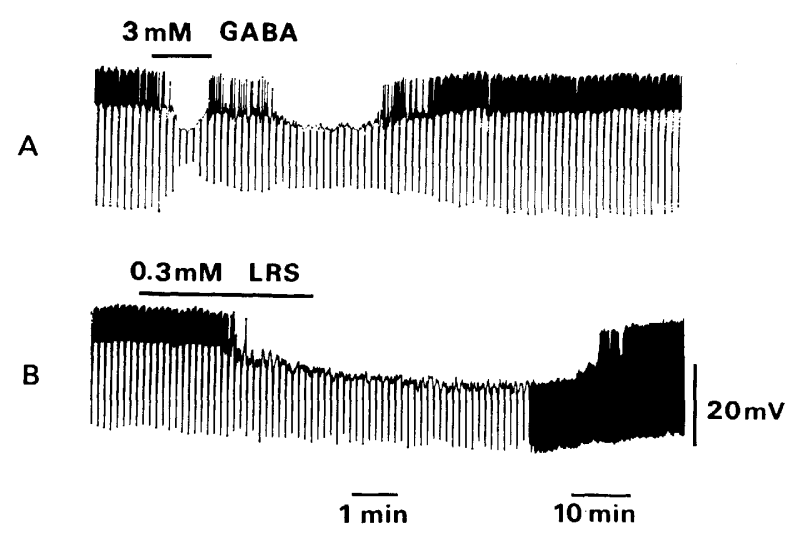

Fig. 2. GABA, and LRS-induced hyperpolarization in the same neuron. Perfusion of GABA or LRS was indicated by each horizontal bars. Resting membrane potential: $-40 \mathrm{mV}$. Downward and upward deflections indicate the membrane input resistance produced by constant square pulses of $3 \mathrm{nA}$ and $1 \mathrm{sec}$ in duration given at each $10 \mathrm{sec}$ intervals and the action potentials (their amplitude was distorted by pen response), respectively. Note that GABA-induced short- and long-lasting hyperpolarizations are accompanied by the increase in membrane conductance. LRS induced only a longlasting hyperpolarization.

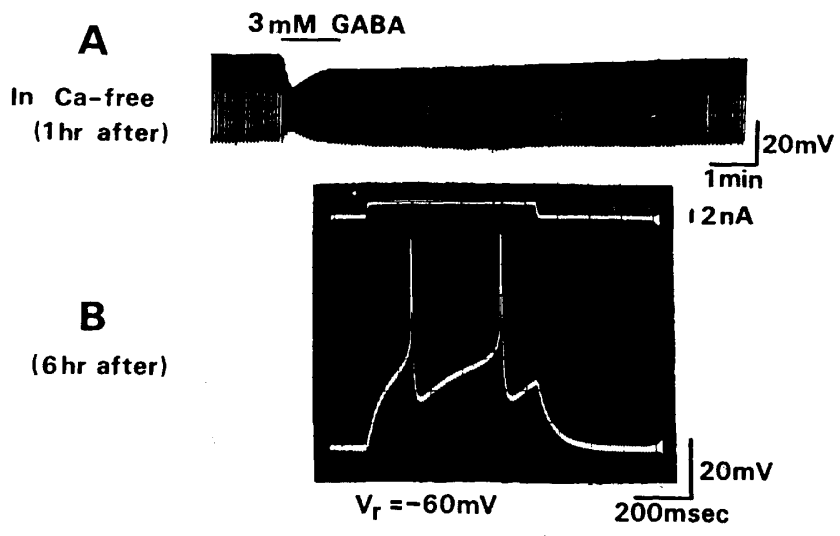

Fig. 3. GABA action in $\mathrm{Ca}^{2+}$-free high $\mathrm{Mg}^{2+}$ medium. $\mathrm{A}$ : $3 \mathrm{~mm} \mathrm{GABA}$ elicited only a short-lasting hyperpolarization. Resting membrane potential: $-40 \mathrm{mV}$. Electrotonic potentials were evoked by current pulses of $1 \mathrm{nA}$ and $500 \mathrm{msec}$ in duration at $5 \mathrm{sec}$ intervals. B: Na-spikes in the same neuron immersed in $\mathrm{Ca}^{2+}$-free high $\mathrm{Mg}^{2+}$ medium for $6 \mathrm{hr}$. Resting membrane potential $\left(V_{\mathrm{r}}\right)$ is increased to $-60 \mathrm{mV}$.

size Na-spike (Fig. 3B). This result suggests that the electrical properties of postsynaptic membrane are intact in $\mathrm{Ca}^{2+}$-free high $\mathrm{Mg}^{2+}$ solution. In this $\mathrm{Ca}^{2+}$ free high $\mathrm{Mg}^{2+}$ medium, GABA elicited only the phase I hyperpolarization which is sensitive to external $\mathrm{Cl}^{-}$concentrations and picrotoxin (Fig. 3A). The GABA- 
induced phase II hyperpolarization as well as the LRS-induced hyperpolarization completely disappeared in $\mathrm{Ca}^{2+}$-free high $\mathrm{Mg}^{2+}$ solution, indicating that the phase II hyperpolarization found in the presence of $\mathrm{Ca}^{2+}$ is probably attributed to a secondary effect by presynaptic origin or $\mathrm{Ca}^{2+}$-activated $\mathrm{K}^{+}$current. Therefore, following voltage clamp experiments were performed in $\mathrm{Ca}^{2+}$-free high $\mathrm{Mg}^{2+}$ medium.

\section{Dose-response relationship of $\mathrm{GABA}$ in $\mathrm{Ca}^{2+}$-free high $\mathrm{Mg}^{2+}$ medium}

The ionic current of the identified neuron of Onchidium was evoked by adding GABA to $\mathrm{Ca}^{2+}$-free high $\mathrm{Mg}^{2+}$ external solution while the solution was flowing. The increase of ionic current depended on GABA concentrations, although the responses were followed with a more rapid desensitization at higher concentration (Fig. 4A). The dose-response curve of GABA was sigmoidal and was almost maximal at $10 \mathrm{~mm}$ GABA (Fig. 4B). It took a wash of about $30 \mathrm{~min}$ to completely reverse the GABA effect at such a high concentration.

According to HIGASHI and NISHI (1982), if it is assumed that GABA combines with the receptor and that the increase of GABA-induced current is proportional to the number of receptors occupied by GABA, then $n(\mathrm{GABA})+$ Receptor $\rightleftharpoons$ $(\mathrm{GABA})_{n}$ (Receptor) $\longrightarrow$ Current increase, where $n$ is the number of GABA molecules required to activate a receptor. At equilibrium,

A

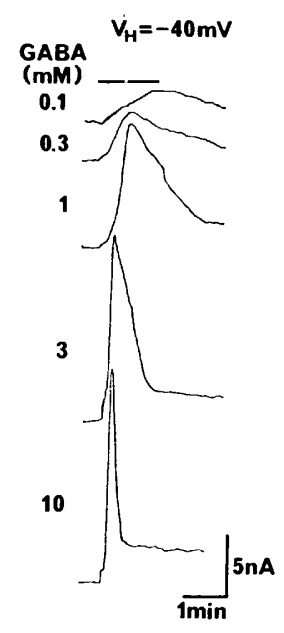

B

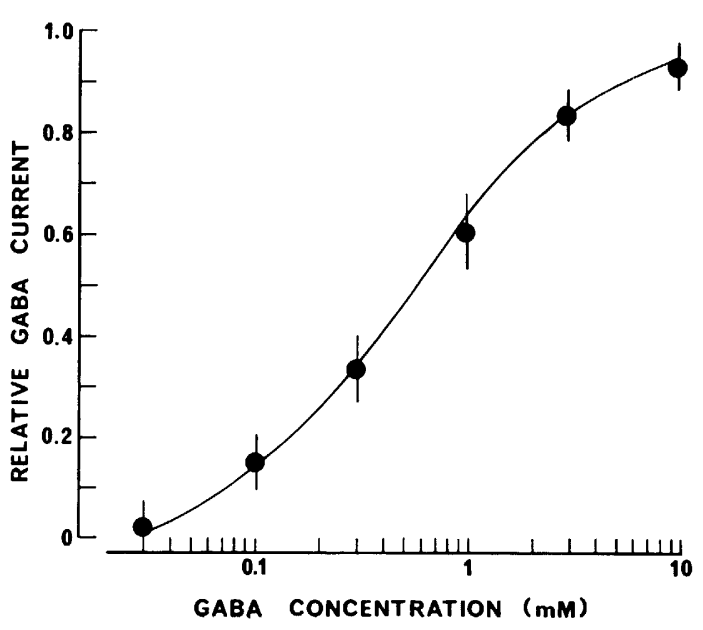

Fig. 4. GABA responses from the identified neuron immersed in $\mathrm{Ca}^{2+}$-free high $\mathrm{Mg}^{2+}$ external solution. A: GABA-induced outward currents. Holding potential $\left(V_{\mathrm{H}}\right)$ was $-40 \mathrm{mV}$. All records were obtained from the same cell. B: dose-response curve of GABA-induced ionic current. A solid line represents a theoretical curve obtained from Eq. 1 in the text. Each filled circle and vertical bars are mean \pm S.D. in 6 neurons. 


$$
I=I_{\max }\left(\frac{a^{n}}{a^{n}+k^{n}}\right)
$$

where $I$ is the GABA induced current, $I_{\max }$ is the maximal value of a GABA induced current, $a$ is the GABA concentration, and $k$ is the geometric mean of the successive microscopic binding constants (AdAMs, 1975). The curve in Fig. 4B is drawn according to Eq. 1, assuming $n=1$ and $k=5.7 \times 10^{-4} \mathrm{M}$. The filled circles represent the mean of 6 experiments. The theoretical curve fits the experimental results well.

3. Ionic mechanism of the $\mathrm{GABA}$-induced current in $\mathrm{Ca}^{2+}$-free high $\mathrm{Mg}^{2+}$ medium

The equilibrium potential for the current activated by $1 \mathrm{~mm}$ GABA $\left(E_{\mathrm{GABA}}\right)$ was determined by evoking the GABA responses after shifting the membrane potential from holding potential $\left(V_{\mathrm{H}}\right)$ of $-40 \mathrm{mV}$ to various membrane potentials (Fig. 5A). In a neuron for which the result is shown in Fig. 5B, $E_{\mathrm{GABA}}$ was about $-60 \mathrm{mV}$. The average value of $E_{\mathrm{GABA}}$ for 7 neurons was $57.2 \pm 4.8 \mathrm{mV}$ (mean S. E.). The $E_{\mathrm{GABA}_{A B}}$ was not affected by either substituting $\mathrm{Tris}^{+}$for $\mathrm{Na}^{+}$or increasing external $\mathrm{K}^{+}$concentration from 9.6 to $19.2 \mathrm{mM}$.

4. Effect of changing external $\mathrm{Cl}^{-}$concentration

Change of extracellular $\mathrm{Cl}^{-}$concentration $\left([\mathrm{Cl}]_{0}\right.$ ) directly affected the GABA-

A

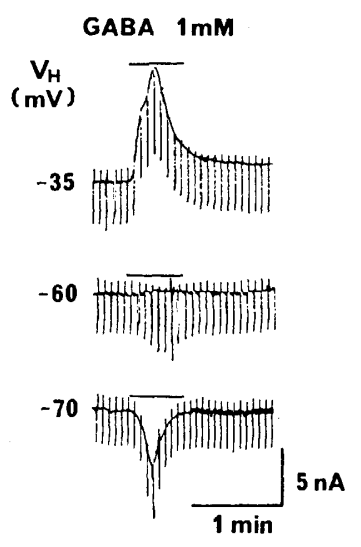

B

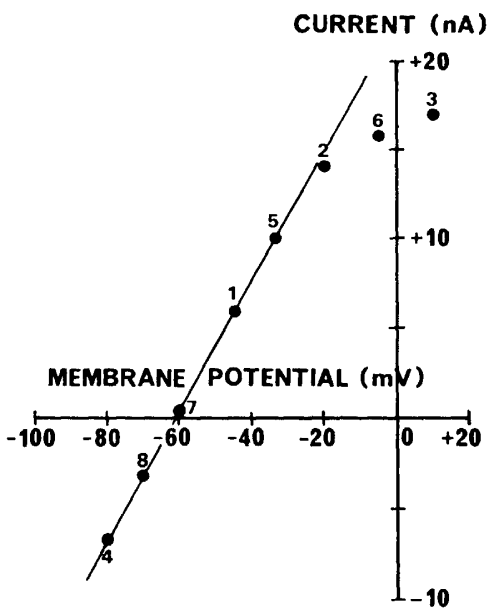

Fig. 5. Determination of GABA equilibrium potential under voltage clamp condition. A: GABA-induced current changes measured at different membrane potentials. Downward deflections indicate conductance changes which were induced by $5 \mathrm{mV}$ hyperpolarizing pulses of $500 \mathrm{msec}$ at $4 \mathrm{sec}$ intervals. B: current-voltage relationship for determination of GABA equilibrium potential $\left(E_{\mathrm{GABA}}\right)$. The application of GABA at $1 \mathrm{~mm}$ concentration was repeated on the same neuron at $30 \mathrm{~min}$ intervals, and in sequence numbered (1-8) beside each filled circle. The graph yields an $E_{\mathrm{GABA}}$ of $-61 \mathrm{mV}$. 


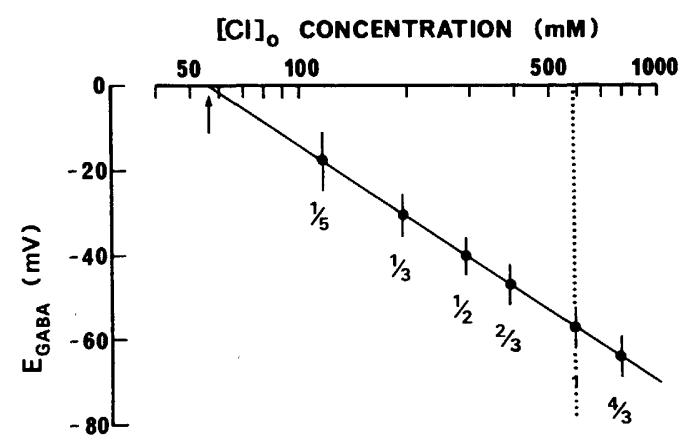

Fig. 6. Dependency of $E_{\mathrm{GABA}}$ on the external $\mathrm{Cl}^{-}$concentration ([Cl]). Each point represents the average value of 7 neurons. Vertical bar for each point shows \pm 1 S.D. of the mean. A straight line represents a slope of $58 \mathrm{mV}$ predicted by the Nernst equation for $\mathrm{Cl}^{-}$electrode. Arrow indicates the theoretical intracellular $\mathrm{Cl}^{-}$concentration $\left([\mathrm{Cl}]_{\mathrm{i}}\right)$.

induced current and its equilibrium potential. When $[\mathrm{Cl}]_{\mathrm{o}}$ was decreased, $E_{\mathrm{GABA}}$ became more positive. A semi-logarithmic plot of the average $E_{\mathrm{GABA}}$ as a function of $[\mathrm{Cl}]_{\mathrm{o}}$ is shown in Fig. 6. A plot of $E_{\mathrm{GABA}}$ versus $[\mathrm{Cl}]_{\mathrm{o}}$ yielded a straight line having a slope of $58 \mathrm{mV}$ for a tenfold change in $[\mathrm{Cl}]_{0}$ as predicted by the Nernst equation for the $\mathrm{Cl}^{-}$equilibrium potential $\left(E_{\mathrm{C} 1}\right)$. Therefore, the GABA-induced current in this neuron is due to a selective increase in $\mathrm{Cl}^{-}$permeability across the cell membrane. Therefore, if it is assumed that $E_{\mathrm{GABA}}$ is equal to $E_{\mathrm{Cl}}$ in $\mathrm{Ca}^{2+}$ free high $\mathrm{Mg}^{2+}$ medium, the intracellular $\mathrm{Cl}^{-}$concentration is estimated to be $57 \mathrm{~mm}$ for this neuron.

\section{DISCUSSION}

In peripheral and central mammalian neurons, LRS is a GABA-like neuronal depressant but is inactive at the postsynaptic, bicuculline- and picrotoxin-sensitive GABA receptor (CURTIS et al., 1974; DAviES and WATKINS, 1974; KrogsGaARDLARSEN et al., 1977; AUlt and EVANS, 1978; BoWERY et al., 1980; WADDINGTON and Cross, 1980; Higashi, Inokuchi, and Nishi, personal communication). It has been suggested that, the receptor for LRS action is located presynaptically (BOWERY et al., 1980). It is well known that synaptic transmitter release is blocked by bathing in low $\mathrm{Ca}^{2+}$ and high $\mathrm{Mg}^{2+}$ medium (KATZ and Miledi, 1965; HubBaRd et al., 1968; LlinAS and NiCHOLSON, 1975; ERULKAR et al., 1978). In our previous paper (OOMURA et al., 1982), the effects of GABA and LRS on the identified Onchidium neuron were investigated in either normal artificial sea water or sea water containing half $\mathrm{Ca}^{2+}$ and 3 times $\mathrm{Mg}^{2+}$. Both solutions gave the same results, in that GABA induced two successive hyperpolarizations and LRS-induced a long-lasting hyperpolarization. Therefore, we concluded that these hyperpolarizations were elicited through direct action on the postsynaptic cell membrane. 
In the present experiments, however, these long-lasting hyperpolarizations were not affected by the complete removal of $\mathrm{Na}^{+}$from normal external solution but blocked by $\mathrm{Ca}^{2+}$-free high $\mathrm{Mg}^{2+}$ solution containing $\mathrm{Co}^{2+}$. Therefore, it may be concluded that the GABA- and LRS-induced long-lasting hyperpolarizations are due to the presynaptic origin. However, we can not completely rule out the possibility that GABA and LRS can directly activate $\mathrm{Ca}^{2+}$ influx through the postsynaptic cell membrane, which would activate $\mathrm{Ca}^{2+}$-dependent $\mathrm{K}^{+}$current and hyperpolarize the membrane (МеECH, 1978; AKAIKE et al., 1983). Such questions require future study. On the other hand, it seems clear that the GABA-induced early hyperpolarization is due to the selective increase of $\mathrm{Cl}^{-}$conductance in the postsynaptic membrane since the amplitude of the hyperpolarization is not different with or without $\mathrm{Ca}^{2+}$ in the external solution.

When GABA or LRS was added to a $\mathrm{Na}^{+}$- and $\mathrm{Ca}^{2+}$-free medium bathing the internally perfused frog dorsal root ganglion cell, only GABA evoked a shortlasting current which was followed by desensitization. The GABA-induced current was not diminished by a successive substitution of $\mathrm{Cs}^{+}$for $\mathrm{K}^{+}$in either external or internal medium, but depended on the external or internal $\mathrm{Cl}^{-}$concentrations (unpublished data). The results are in agreement with NISHI and his coworkers' reports by using microelectrode technique (1974). It is clear from these results that GABA has a direct action on the postsynaptic soma membrane and that GABA-induced current results from the increase of $\mathrm{Cl}^{-}$permeability.

In the muscle fibers of crayfish where the desensitization of GABA-induced current is less pronounced, the Hill coefficients of 2 and 3 have been reported by TAKeUCHI and TAKeUCHI (1967) and Feltz (1971), respectively. In the present study, GABA-induced $I_{\mathrm{C} 1}$ of the Onchidium neuron gave Hill coefficient, $n=1$, for the dose-response curve. Such a low Hill coefficient may be explained from the rapid desensitization in this identified neuron.

The authors thank Dr. H. Higashi and Dr. D. Carpenter for their helpful discussions in the preparation of this manuscript. The present study was partially supported by a Grant-inAid for Scientific Research (No. 577075) from the Ministry of Education, Science and Culture of Japan.

\section{REFERENCES}

Adams, P. R. (1975) An analysis of the dose-response curve at voltage-clamped frog-endplate. Pflügers Arch., 360: 145-153.

Akaike, N., Brown, A. M., Dahl, G., Higashi, H. Isenberg, G., Tsuda, Y.. and Yatani, A. (1983) Voltage-dependent activation of $\mathrm{K}$ current in Helix neurons by endogenous cellular calcium. J. Physiol. (Lond.), 334: 309-324.

Ault, B. and Evans, R. H. (1978) Central depressant action of baclofen. J. Physiol. (Lond.), 284: $131 \mathrm{P}$.

Bowery, N. G., Doble, A., Hill, D. R., Hudson, A. L., Shaw, J., and Turnbull, M. J. (1980) $\beta$-Chlorophenyl GABA (Baclofen) is a selective ligand for a novel GABA receptor on nerve terminals. Brain Res. Bull. (Suppl. 2), 5: 497-502. 
Curtis, D. R., Game, C. J. A., Hohnston, G. A. R., and McCulloch, R. M. (1974) Central effects of $\beta$-( $\rho$-chlorophenyl)- $\gamma$-aminobutyric acid. Brain Res., 70: 493-499.

Davidoff, R. A. (1978) Pharmacology of spasticity. Neurology, 28: 46-51.

DAvies, J. and WATkins, J. C. (1974) The action of $\beta$-phenyl-GABA derivatives on neurones of the cat cerebral cortex. Brain Res., 70: 501-505.

Erulkar, S. D., RAHAMimoff, R., and Rotshenker, S. (1978) Quelling of spontaneous transmitter release by nerve impulses in low extracellular calcium solutions. J. Physiol. (Lond.), 278: 491-500.

Feltz, A. (1971) Competitive interaction of $\beta$-guanidino-propionic acid and $\gamma$-aminobutyric acid on the muscle fibre of the crayfish. J. Physiol. (Lond.), 216: 391-401.

Fox, S., Krnjevic, K., Morris, M. E., Puil, E, and Werman, R. (1978) Action of baclofen on mammalian synaptic transmission. Neuroscience, 3: 495-515.

HigASHI, H. and NISHI, S. (1982) 5-Hydroxytryptamine receptors of visceral primary afferent neurones on rabbit nodose ganglia. J. Physiol. (Lond.), 323: 543-567.

Hubbard, J. I., Jones, S. F., and Landau, E. M. (1968) On the mechanism by which calcium and magnesium affect the release of transmitter by nerve impulses. J. Physiol. (Lond.), 196: 75-86.

KATZ, B. and MiLEDI, R. (1965) The effect of calcium on acetylcholine release from motor nerve terminals. Proc. R. Soc. Lond. (Biol.), 161: 496-503.

KrogsgaArd-Larsen, P., Johnston, G. A. R., Lodge, D., and Curtis, D. R. (1977) A new class of GABA agonist. Nature, 268: 53-55.

Llinas, R. and Nicholson, C. (1975) Calcium in depolarization-secretion coupling: An aequorin study in squid giant synapse. Proc. Natl. Acad. Sci. U.S.A., 72: 187-190.

MeEch, R. W. (1978) Calcium-dependent potassium activation in nervous tissues. Annu. Rev. Biophys. Bioeng., 7 : 1-18.

NAIK, S. R., Guidotti, A., and CostA, E. (1976) Central GABA receptor agonist: Comparison of muscimol and baclofen. Neuropharmacology, 15: 479-484.

Nishi, S., Minota, S., and Karczmar, A. G. (1974) Primary afferent neurones: The ionic mechanism of GABA-mediated depolarization. Neuropharmaco'ogy, 13: 215-219.

Oomura, Y., Maruhashi, J., Shimizu, N., and Kato, M. (1979) GABA receptors and ionic channels in Onchidium neuron. Brain Res Bull., 4: 178-180.

Oomura, Y., Ooyama, H., and Sawada, M. (1974) Analysis of hyperpolarizations induced by glutamate and acetylcholine on Onchidium neurones. J. Physiol. (Lond.), 243: 321-341.

Oomura, Y., Shimizu, N., and Maruhashi, J. (1982) Chemical structure of the GABA receptive membrane in Onchidium neurons studied by electrophysiological analysis. In: Problems in GABA Research from Brain to Bacteria, ed. by OKADA, Y. and RoBERTs, E. Excerpta Medica, Amsterdam, Oxford, and Princeton, pp. 69-79.

Potashner, S. J. (1979) Baclofen: Effects on amino acid release and metabolism in slices of guinea pig cerebral cortex. J. Neurochem., 32: 103-109.

TAKEUCHI, A. and TAKEUCHI, N. (1967) Anion permeability of the inhibitory postsynaptic membrane of the crayfish neuromuscular junction. J. Physiol. (Lond.), 191: 575-590.

Waddington, J. L. and Cross, A. J. (1979) Baclofen and muscimol: Behavioural and neurochemical sequelae of unilateral intranigral administration and effects on ${ }^{3} \mathrm{H}-\mathrm{GABA}$ receptor binding. Naunyn-Schmiedebergs Arch. Pharmacol., 306: 275-280.

WAdDington, J. L. and Cross, A. J. (1980) GABA-ergic properties of baclofen in vivo and in vitro. Brain Res. Bull. (Suppl. 2), 5: 503-505. 